\title{
Effect of aorto-coronary grafts and native vessel patency on the occurrence of angina pectoris after coronary bypass surgery ${ }^{1}$
}

\author{
M. H. Frick, P.-T. Harjola, and M. Valle \\ From the Cardiovascular Laboratory, First Department of Medicine, and from Third Department of Surgery, \\ and First Department of Radiology, University Central Hospital, Helsinki, Finland
}

Exercise testing of 52 patients on average II months after coronary bypass surgery for the relief of angina pectoris disclosed improvement in total work $(P<0.001)$, maximal tolerated load $(P<0.001)$, maximal heart rate $(P<0.0 I)$, and reduction of maximal $S T$ segment depression $(P<0.00 I)$ in a group of 36 patients with all grafts patent. In another group of 16 patients with one or more grafts occluded the only significant change was a reduction in the maximal $S T$ segment depression $(P<0.01)$.

Early and late postoperative angiograms showed that 75 per cent of the grafts that became occluded were already closed a few weeks after operation. Occluded grafts were accompanied by persistence of collaterals, which disappeared or diminished in the majority of patients with patent grafts. Progression in native vessel lesions occurred in 40 per cent of patients. It was related to the grafting procedure $(P<0.01)$ but not to the state of grafts. The change in native vessels and other variables studied was equal in the patent and occluded graft groups, justifying the conclusion that graft patency was the major factor alleviating angina after operation.

Aortocoronary bypass surgery in ischaemic heart disease (Favaloro, 1969; Effler, Favaloro, and Groves, 1970; Johnson, Flemma, and Lepley, 1970) has unanimously been reported to be effective in relieving anginal pain in the great majority of patients (Mitchel et al., 1970; Sabiston, 1971; Spencer et al., 197I ; Anderson et al., 1972; Manley et al., 1972; Morris et al., 1972; Guiney et al., 1973). This relief has been impressive and rapid, in contrast to the rather delayed effect, if any, of internal mammary artery implantation. The most evident reason for this effectiveness, namely increased myocardial perfusion distal to coronary artery obstructions, has not gained universal acceptance. Additional and/or alternative mechanisms have been proposed, including a nonspecific effect of surgery, postoperative myocardial infarction making pain-triggering ischaemic areas painless, and, most recently, possible destruction of the pericoronary nerve plexus by the surgical procedure (Soloff, 1973).

No series including randomly allocated nonoperated controls has been published, but some Received 29 July 1974.

${ }^{1}$ Supported by a grant from the Finnish State Council for Medical Research. reports relating the effect of bypass surgery to graft patency have appeared (Ross et al., 1972; Achuff et al., 1972; Matlof et al., 1973; Alderman et al., 1973; Lapin et al., 1973; Bartel et al., 1973). Since the relief of anginal pain is evidently multifactorial, the aim of this report is to correlate graft patency, native lesion progression, collaterals, and new infarctions with symptomatic improvement of angina, determined by objective functional status on exercise testing.

\section{Methods}

\section{Patients studied}

One hundred and six aortocoronary bypass operations were performed on 103 patients in Helsinki University Central Hospital between September 1970 and December 1973. Ninety-two of these were done electively and without other concomitant cardiac surgery, with a hospital mortality of 5.4 per cent. Fifty-two of these patients have had repeated postoperative coronary angiographies and are the subject of this report.

Fifty-two patients had had angina for at least 6 months before operation and $32(62 \%)$ had had one or more myocardial infarcts. The patients were referred after medical treatment with beta-adrenergic inhibitors, coronary vasodilators, and short-acting nitroglycerin 
had failed to enable them to return to work. The severity of angina, according to the New York Heart Association classification, was as follows: I 2 patients in class II, 23 patients in class III, and I7 patients in class IV $77 \%$ in classes III and IV). The angina was stable in 47 and unstable in 5 . There were 43 men and 9 women with an age range from 30 to 64 (mean 47.5 ) years.

\section{Angiography and surgical techniques}

Preoperative selective coronary angiography was performed by the Judkins' technique with the following findings: 23 patients had 3-vessel disease, 23 patients had 2-vessel disease, and 6 patients had I-vessel disease ( 4 in the left anterior descending coronary artery). A stenosis exceeding 50 per cent was considered significant. The technique of the postoperative angiographic studies has been published in detail elsewhere (Valle, 1973). In brief, it consisted of selective native vessel and graft injections when possible. In a few patients the grafts were not entered and an aortic root injection was made. Early postoperative angiography was performed in 50 patients $(96 \%)$ during the postoperative hospital stay to assess early patency of the grafts. In 2 patients the visualization of the grafts was performed somewhat later. All patients had a second postoperative angiography on an average of II months (6 to 16 months) after operation. At this study all the grafts and native vessels were injected in 43 patients ( $83 \%$ ).

The obstructions in the left main, left anterior descending, left circumflex, and right coronary artery were graded as follows: 0 : no obstruction, $1:<25$ per cent obstruction, 2: 25 to 50 per cent obstruction, $3: 50$ to 75 per cent obstruction, 4: subtotal occlusion, and 5: total occlusion. The sum of the obstructions formed the coronary score for each individual patient (Table 2). In the analysis of postoperative angiograms progression of native vessel lesions was accepted if there was an increase of at least one grade in severity. Special attention was paid to the presence or absence of collaterals and to the direction of their filling.

All coronary reconstructions were performed under cardiopulmonary bypass employing elective fibrillation for the time required to complete the anastomosis except in a few cases done on a beating heart. When a completely dry field was necessary the aortic root was clamped. The distal anastomosis was performed using at first $7-0$ Tevdek and later $6-0$ or $7-0$ Prolene sutures. The distal anastomosis was done end-to-side except in the few cases where the same graft was used to bypass lesions in two vessels, usually the left anterior descending and its diagonal branch. In these cases the proximal anastomosis was done side-to-side. After completing the distal anastomosis the heart was defibrillated and the graft was anastomosed with the ascending aorta while the heart was beating.

Altogether II 5 grafts were inserted. There were 9 single graft, 23 double graft, and 20 triple graft procedures. With the exception of $4^{\prime} \mathrm{Y}$ ' grafts used in the early part of the series, each reversed saphenous vein graft had a separate anastomosis with the ascending aorta. The left internal mammary artery was used as a pedicle in 34 instances. It was exclusively used to bypass obstructions in the left anterior descending and/or its diagonal branch. Of the single venous grafts, 6 were used to bypass the left anterior descending and 3 right coronary artery lesions. In addition to grafting and small instrumental endarterectomy when required ( 5 arteries in 5 patients), gas endarterectomy was used in 15 patients on a total of 17 coronary arteries.

\section{Exercise testing and other methods}

Exercise testing was performed using an electrically braked bicycle ergometer (Elema-Schönander) and applying successively increased loads without intervening pauses. Each load lasted for 4 minutes and loading was increased until dyspnoea and/or angina requiring short-acting nitroglycerin was evoked. Before and 5 minutes after the exercise, a standard 12-lead electrocardiogram was recorded. During the exercise, chestlead electrodes in VI-6 positions were used and the electrocardiogram was continuously monitored and recorded once a minute. The recorded electrocardiograms were analysed for the presence and degree of either horizontal or downward sloping ST segment depression.

During preoperative exercise testing all subjects were stressed to subjective maximal exercise irrespective of the ST segment depressions (maximal $13 \mathrm{~mm}$ ). At the postoperative studies, done a day before the follow-up angiography (average II months after the operation), the patients with angina were similarly tested. In testing those patients who were symptomless after surgery, the intensity of the exercise was increased to produce at least a heart rate greater than 85 per cent of age-predicted maximum.

The variables used to assess the exercise tolerance were as follows: total work (TW) in Newton metres $(\mathrm{TW}, \mathrm{Nm})=$ the sum of each pedalled load multiplied by the respective time in minutes, maximal tolerated load (MaxL, Nm/min), maximal heart rate (maxHR), and maximal ST segment depression ( $\max$ $\left.\mathrm{ST}_{\mathrm{d}}, \mathrm{mm}\right)$.

Postoperatively every patient had an exercise test. The 5 patients with unstable angina were not tested preoperatively. Based on several years of experience in exercise testing (Frick, 197I) the total work of these patients was deliberately overestimated as $5.8 \mathrm{kNm}$ and the maxL as $1.5 \mathrm{kNm} / \mathrm{min}$. No data for maxHR and $\operatorname{maxST}_{\mathrm{d}}$ for these patients were tabulated. In assessing the maxHR, the effect of previous postoperative therapy with beta-adrenergic inhibitors, which decrease the exercise heart rate, is of special importance. Twenty-six patients were without these drugs on both testing situations; I2 had them on both occasions. In addition the results were accepted from 12 patients who were on these compounds when they had the lower exercise tolerance. The same rule was applied to treatment by digitalis in analysing the maxST ${ }_{\mathrm{d}}$ (Frick, Virtanen, and Sävelä, 1972), leading to exclusion of the data from 6 patients.

Changes in serial postoperative electrocardiograms were analysed with special attention to the appearance of new pathological $Q$ waves and/or deep persistent $T$ 
wave inversion. The heart volumes were measured from biplane chest $x$-rays exposed without reference to the cardiac cycle. The ellipsoid approximation method was used (Jonsell, I939).

Student's t-test was used to test the significance of the difference between sample means. $\chi^{2}$ test was applied in testing the significance of difference in frequency distribution of tested variables in different subgroups.

\section{Results}

Early postoperative angiography disclosed I3 occluded grafts representing an II per cent occlusion rate. In the late postoperative angiographic studies 5 additional grafts were found occluded, increasing the graft occlusion rate to I6 per cent at I I months. At the time of retesting the exercise tolerance there were 16 patients with one or more occluded grafts (group O) and 36 patients with all grafts patent (group P).

All the variables related to the objective exercise testing were significantly improved in group $\mathbf{P}$ (Table I). TW, which is the most sensitive parameter combining both load and endurance, was increased by 158 per cent in group $P$ (Fig. I). The only significant change in group $\mathrm{O}$ was less maxST on retesting. To explore further if any variable other than graft patency accounted for these differences, a number of pre-, intra- and postoperative factors were analysed. The pertinent preoperative data are given in Table 2, and reveal that the only significant difference between the groups was a greater

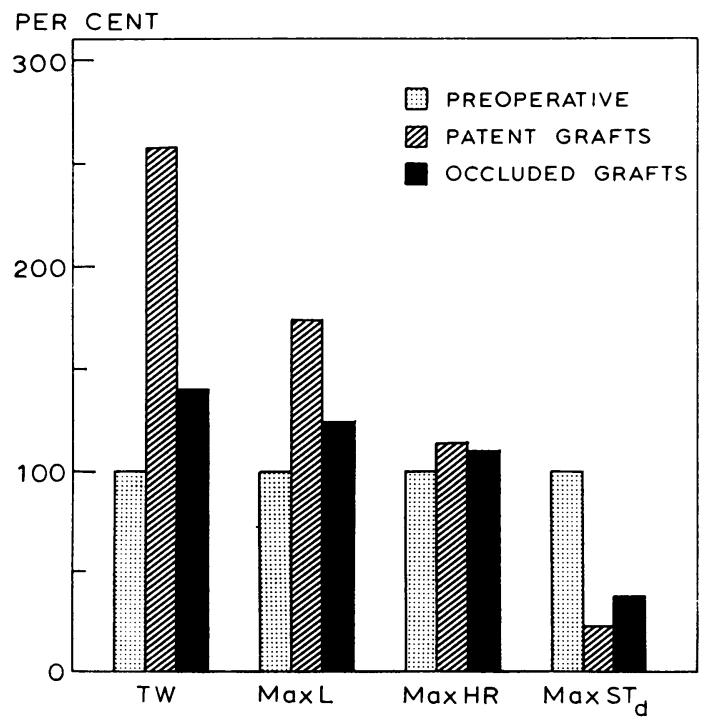

FIG. Percentage changes in different exercise variables. Abbreviations in the text. proportion of patients with previous myocardial infarction in group $\mathrm{O}$.

The number of inserted grafts ranged from $I$ to 3 , mean 2.I, in group $P$ and from 2 to 3, mean 2.5, in group $O$. There were 12 patients with postoperative infarctions $(23 \%)$. Seven of these were in group $\mathbf{P}$ $(19.4 \%)$ and 5 in group $O(31.3 \%) ; \chi^{2}=0.873$, $\mathrm{P}=0.30$.

Analysis of postoperative heart volumes revealed that the means were $939 \mathrm{ml} \pm 169$ in group $P$ and $993 \mathrm{ml} \pm 245$ in group $\mathrm{O}$; the difference is not significant. The number of patients with visible collaterals was reduced in group $P$, being 13 of 30 $(43.3 \%)$ patients with native vessel angiography, as compared to II of $13(84.6 \%)$ in group $\mathrm{O}\left(\chi^{2}=\right.$ $6.29, P<0.02)$. In addition to the number of patients entirely without visible collaterals in group $P, 9$ patients in this group showed pronounced decrease in the number and filling of collaterals.

The number of patients with progression in native vessel lesions did not differ significantly between the groups: 37.9 per cent in group $\mathrm{P}$ and 46.I per cent in group $O\left(\chi^{2}=0.25, P=0.50\right)$. It occurred in a total of 17 patients, representing 39.5 per cent of patients with combined graft and native vessel angiography. This analysis includes the gas endarterectomized vessels, 29 per cent of which showed progression. These arteries and the totally occluded vessels were excluded from the analysis on the role of grafting per se in the subsequent progression of preoperative lesions. This showed that progression occurred in only 2 of 27 non-grafted coronary arteries $(7.4 \%$ ) whereas it occurred in 12 of 57 grafted arteries (21.1\%); $\chi^{2}=7.68, \mathrm{P}<0.01$. Progression was not related to the patency or occlusion of the grafts $\left(\chi^{2}=0.31, \quad \mathbf{P}=0.50\right)$. The numbers were too small for analysis of the role of early or late occlusion of the grafts. Eight of the 12 lesions progressed from grade 3 or 4 to grade 5 . Eleven lesions were proximal to the graft anastomosis and one just at the anastomosis.

\section{Discussion}

Several factors enter into the problem of assessing the efficacy of bypass surgery in patients with angina pectoris. One of the most prominent is the desire for improvement on the part of both patient and physician. The influence of this can be avoided to some degree by the use of objective maximal exercise testing instead of subjective evaluation. This fact has emerged from most of the studies in which symptomatic improvement has been compared with the data of objective testing (Ross et al., 1972; Achuff et al., 1972; Matlof et al., 1973; Lapin et al., 1973; Bartel et al., 1973). It has been repeatedly stated (Friedberg, 1970; Spodick, 1971, 
TABLE I Comparative pre-and postoperative exercise data in relation to graft patency

\begin{tabular}{|c|c|c|c|c|c|c|}
\hline & $\begin{array}{l}\text { Patent grafts } \\
\text { ( } 36 \text { patients) } \\
\text { Preop. }\end{array}$ & Postop. & $P$ & $\begin{array}{l}\text { Occluded grafts } \\
\text { (I6 patients) } \\
\text { Preop. }\end{array}$ & Postop. & $P$ \\
\hline Total work (kNm) & $15.8 \pm 13.3^{\star}$ & $40.9 \pm 22.0$ & $<0.001$ & $I 8.7 \pm I 4.6$ & $26.3 \pm 18.8$ & NS \\
\hline Max. load (kNm/min) & $3.5 \pm 2.0$ & $6.1 \pm 2.1$ & & $4.3 \pm 1.9$ & $5.3 \pm 2.1$ & \\
\hline Max. heart rate (bts/min) & $118 \pm 18$ & $136 \pm 19$ & $<0.01$ & $117 \pm 22$ & $129 \pm 25$ & NS \\
\hline Max. ST depression (mm) & $3.0 \pm 2.7$ & $0.7 \pm 1.1$ & $<0.001$ & $3.1 \pm 1.8$ & $1.2 \pm 0.9$ & $<0.01$ \\
\hline
\end{tabular}

$\star$ Mean \pm standard deviation; NS $=$ not significant $(>0.05)$.

Conversion from SI Units - I kNm $\approx 102 \mathrm{kpm}$.

1973b) that the lack of randomly allocated nonoperated control patients limits the value of postoperative studies. It is certainly true that the psychogenic component could be excluded with some certainty by the use of random non-operated controls. This approach would not, however, eliminate the possible factors other than graft patency that are associated with the operation and influence the results, e.g. myocardial infarction, local cardiac denervation, and subsequent progression of the lesions in the native vessels. Thus, the mechanism of pain relief would remain unsolved. Since it is unthinkable to insert sham grafts, the alternative is to follow the operated patients and perform comparative studies on patients with patent versus occluded grafts by analysing at the same time the degree of similarity of the groups with respect to variables known to be associated with the genesis of angina pectoris. This approach has been followed in the present study.

On the other hand, the inclusion of randomly allocated non-operated control patients is essential in studies exploring the possible effect of bypass surgery on longevity. As one of the participating centres in the European Multicentre Trial studying the prognostic effect of bypass surgery we have been involved in randomized bypass surgery for one year. A number of patients randomly allocated to the non-surgical group have reacted with mental depression and some with suicidal thoughts. It is apparent that if these patients were used as controls in a study on the effectiveness of bypass surgery on angina pectoris a bias in favour of surgical therapy would be introduced.

The analysis of the preoperative similarity of the groups with dissimilar subsequent outcomes (Table 2) disclosed more patients with previous myocardial infarctions in group $\mathrm{O}$ as the sole difference. It has been observed that preoperative infarction reduces the relief of angina by bypass surgery (Alderman et al., 1973). However, an analysis of graft patency in relation to previous infarctions was not included. Since the higher prevalence of patients with previous myocardial infarction in the present series did not render the preoperative exercise tolerance of group $O$ inferior to that of group $P$ (Table 2), it can hardly account for the different response to surgery (Table I, Fig. I) except by causing more graft occlusions.

No intraoperative factor responsible for the

TABLE 2 Preoperative characteristics of the series

\begin{tabular}{lccc}
\hline & $\begin{array}{l}\text { Patent } \\
\text { graft group }\end{array}$ & $\begin{array}{l}\text { Occluded } \\
\text { graft group }\end{array}$ & $P$ \\
\hline Age (yr) & $30-64,46.9^{\star}$ & $36-60,48.5$ & NS \\
Coronary score & $3-17,10.9$ & $7-17,11.0$ & NS \\
Duration of angina, years & $12-20,5.2$ & 1-16,5.1. & NS \\
No. of patients with collaterals & $32(89 \%)$ & $14(94 \%)$ & NS \\
No. of patients with previous infarctions & $18(50 \%)$ & $14(88 \%)$ & $<0.02$ \\
Total work $(\mathrm{kNm})$ & $15.8 \pm 13.3 \neq$ & $18.7 \pm 14.6$ & NS \\
Max. load $(\mathrm{kNm} / \mathrm{min})$ & $3.5 \pm 2.0$ & $4.3 \pm 1.9$ & NS \\
Heart volume (ml) & $909 \pm 189$ & $1011 \pm 196$ & NS \\
\hline
\end{tabular}

\footnotetext{
$\star$ Range and mean.

$\dagger$ See text.

$\ddagger$ Mean \pm standard deviation.

NS $=$ not significant.

Conversion from SI Units - I $\mathrm{kNm} \approx 102 \mathrm{kpm}$.
} 
difference in postoperative exercise response could be found. In the analysis of postoperative data the behaviour of collaterals was impressive. They disappeared completely or diminished in patients with patent grafts, whereas they persisted in patients with occluded grafts. This finding has been verified in a larger series (Valle, 1973), suggesting that pressure gradients disappear when poststenotic segments are perfused via grafts. If the thesis is accepted that visible collaterals in patients with ischaemic heart disease signify reduced poststenotic perfusion pressures with resulting ischaemia in appropriate stressful situations, the disappearance of the preoperative collateral network in combination with patent grafts suggests a causal relation between graft patency and the effect of bypass surgery on effort angina. It is pertinent to recall that the present series contained only one patient with all grafts occluded, others in group $\mathrm{O}$ having at least one patent graft. Yet the group as a whole did not respond favourably to surgery. This is in accord with the findings of others (Lapin et al., 1973). The percentage changes in group $\mathrm{O}$ in the different variables characterizing exercise tolerance (Fig. I) were somewhat larger than we are accustomed to find in the placebo phase of double-blind trials with beta-adrenergic inhibitors (Frick and Katila, I970) and coronary 'vasodilators' (Frick and Somer, 197I). They apparently represent the combined effect of the psychogenic impact of surgery, patency of some grafts, and other factors discussed above. It is likewise apparent that a similar fraction of the response of group $P$ is to be similarly accounted for.

Although almost all $(92 \%)$ of the lesions that progressed were proximal to the grafts, these changes cannot be considered to be without local circulatory consequences, e.g. by occlusion of septal branches in the progression of lesions in the left anterior descending artery. However, the incidence of progression in native vessel lesions was the same in the two groups and cannot be held responsible for the difference in response of effort angina. The same reasoning applies to the incidence of new postoperative myocardial infarctions, which was higher than usually reported (Kaltman, 1973) but lower than in the series of Achuff et al. (1972).

Data on the late effects of bypass surgery on heart volume or left ventricular function in relation to graft patency are at variance (Ross et al., 1972; Achuff et al., 1972; Bourassa et al., 1972; Kline et al., 1972; Lapin et al., 1973; Griffith et al., 1973). The contribution of improved left ventricular function to the relief of angina is not a straightforward one but depends on the intricate balance between energy-requiring increased contractility and energy-saving reduced wall stress consequent upon reduction of left ventricular volume. Only heart volume responses were monitored in the present study, and no significant differences were observed between the subgroups.

In summary we conclude that exercise tolerance restricted by angina pectoris is significantly improved after coronary bypass surgery provided all the grafts remain patent. Though some improvement is observed in patients with one or more occluded grafts, they do not as a group exhibit significant improvement.

\section{References}

Achuff, S., Griffith, L., Humphries, J. O., Conti, C. R., Brawley, R., Gott, V., and Ross, R. (1972). Myocardial damage after aorto-coronary vein bypass surgery (abstract). Fournal of Clinical Investigation, 51, ra.

Alderman, E. L., Matlof, H. J., Wexler, L., Shumway, N. E., and Harrison, D. C. (I973). Results of direct coronaryartery surgery for the treatment of angina pectoris. New England fournal of Medicine, 288, 535.

Anderson, R. P., Hodam, R., Wood, J., and Starr, A. (1972). Direct revascularization of the heart. Early clinical experience with 200 patients. Fournal of Thoracic and Cardiovascular Surgery, 63, 353.

Bartel, A. G., Behar, V. S., Peter, R. H., Orgain, E. S., and Kong, Y. (1973). Exercise stress testing in evaluation of aortocoronary bypass surgery. Report of 123 patients. Circulation, 48, $14 \mathrm{I}$.

Bourassa, M. G., Lésperance, J., Campeau, L., and Saltiel, J. (1972). Fate of left ventricular contraction following aortocoronary venous grafts. Early and late postoperative modifications. Circulation, 46, 724.

Effler, D. B., Favaloro, R. G., and Groves, L. K. (1970). Coronary artery surgery utilizing saphenous vein graft techniques: clinical experience with 224 operations. Fournal of Thoracic and Cardiovascular Surgery, 59, 147.

Favaloro, R. G. (1969). Saphenous vein graft in the surgical treatment of coronary artery disease: operative technique. Fournal of Thoracic and Cardiovascular Surgery, 58, 178 .

Frick, M. H. (197I). Exercise performance of cardiac patients. In Frontiers of Fitness, p. 345. Ed. by R. J. Shephard. Charles C. Thomas, Springfield, Illinois.

Frick, M. H., and Katila, M. (1970). Cardio-selective betaadrenergic inhibition by practolol in angina pectoris. Annals of Clinical Research, 2, 96.

Frick, M. H., and Somer, T. (I97I). Assessment of the effect of long-term dipyridamole in angina pectoris by atrial pacing and physical exercise. Annals of Clinical Research, 3 , 143 .

Frick, M. H., Virtanen, K., and Sävelä, J. (1972). Modification of digitalis-induced electrocardiographic changes by propranolol and potassium. Annals of Clinical Research, $4,213$.

Friedberg, C. K. (1970). Management of ischemic heart disease: medical view of results of surgical treatment. In Abstracts of VI World Congress of Cardiology. Cardiovascular Research, $4,42$.

Griffith, L. S. C., Achuff, S. C., Conti, C. R., Humphries, J. O., Brawley, R. K., Gott, V. L., and Ross, R. S. (1973). Changes in intrinsic coronary circulation and segmental ventricular motion after saphenous-vein coronary bypass graft surgery. New England fournal of Medicine, 288, 589.

Guiney, T. E., Rubenstein, J. J., Sanders, C. A., and Mundth, E. D. (1973). Functional evaluation of coronary bypass 
surgery by exercise testing and oxygen consumption. Circulation, 48, Suppl. III, I4I.

Johnson, W. D., Flemma, R. J., and Lepley, D., Jr. (1970). Direct coronary surgery utilizing multiple-vein bypass grafts. Annals of Thoracic Surgery, 9, 436.

Jonsell, S. (1939). A method for the determination of the heart size by teleroentgenography (a heart volume index). Acta Radiologica, 20, 325.

Kaltman, A. J. (1973). Complications of aortocoronary bypass surgery. American Heart fournal, 86, 705.

Kline, S., Apstein, C., Baltaxe, H., and Levin, D. (1972). Left ventricular function after aorto-coronary bypass. Circulation, 46, Suppl. II, 23.

Lapin, E. S., Murray, J. A., Bruce, R. A., and Winterscheid, L. (1973). Changes in maximal exercise performance in the evaluation of saphenous vein bypass surgery. Circulation, 47, II64.

Manley, J. C., Johnson, W. D., Flemma, R. J., and Lepley, D. (1972). Objective evaluation of the effects of direct myocardial revascularization on ventricular performance utilizing submaximal ergometer exercise testing. American Fournal of Cardiology, 29, 277.

Matlof, H. J., Alderman, E. L., Wexler, L., Shumway, N. E., and Harrison, D. C. (1973). What is the relationship between the response of angina to coronary surgery and anatomical success ? Circulation, 48, Suppl. III, I68.

Mitchel, B. F., Adam, M., Lambert, C. J., Sungu, U., and Shiekh, S. (1970). Ascending aorta-to-coronary artery saphenous vein bypass grafts. Fournal of Thoracic and Cardiovascular Surgery, 60, 457.

Morris, G. C., Jr., Reul, G. J., Howell, J. F., Crawford, E. S.,
Chapman, D. W., Beazley, H. L., Winters, W. L., Peterson, P. K., and Lewis, J. M. (1972). Follow-up results of distal coronary artery bypass for ischaemic heart disease. American fournal of Cardiology, 29, 180.

Ross, D., Sutton, R., Dow, J., Gonzales-Lavin, L., Hendrix, G., Jefferson, K., McDonald, L., Petch, M., Smithen, C., and Sowton, E. (1972). Venous graft surgery in treatment of coronary heart disease. British Medical fournal, 2, 644 .

Sabiston, D. C., Jr. (I97I). Direct revascularization procedure in the management of myocardial ischemia. Circulation, 43, 175 .

Soloff, L. A. (1973). Effects of coronary bypass procedures. New England fournal of Medicine, 288, 1302.

Spencer, F. C., Green, G. E., Tice, D. A., and Glassman, E. (I97I). Bypass grafting for occlusive disease of the coronary arteries. A report of experience with 195 patients. Annals of Surgery, 173, I029.

Spodick, D. H. (197I). Revascularization of the heartnumerators in search of denominators. American Heart Fournal, 81, 149.

Spodick, D. H. (1973a). The surgical mystique and the double standard. American Heart fournal, 85, 579.

Spodick, D. H. (1973b). Coronary bypass procedures. New England fournal of Medicine, 288, 1076.

Valle, M. (1973). Postoperative coronary angiography. Acta Radiologica, Suppl. 333.

Requests for reprints to Dr. M. H. Frick, Cardiovascular Laboratory, First Department of Medicine, University Central Hospital, Haartmaninkatu 4, 00290 Helsinki 29, Finland. 